\title{
Validation of the Factor Structure of the Five Facets of Mindfulness Questionnaire in men diagnosed with advanced prostate cancer
}

\author{
Kirstyn Laurie, ${ }^{1,2}$ Melissa K. Hyde, ${ }^{1,2}$ Stephen J. Lepore, ${ }^{3}$ and Suzanne K. Chambers, $, 2,4,5,6^{*}$ \\ ${ }^{1}$ Menzies Health Institute Queensland, Griffith University, Gold Coast, QLD, Australia \\ ${ }^{2}$ Cancer Council Queensland, Brisbane, QLD, Australia \\ ${ }^{3}$ Department of Social and Behavioral Sciences, College of Public Health, Temple \\ University, PA, USA \\ ${ }^{4}$ Prostate Cancer Foundation of Australia, Sydney, NSW, Australia \\ ${ }^{5}$ Exercise Medicine Research Institute, Edith Cowan University, Perth, WA, Australia \\ ${ }^{6}$ Institute for Resilient Regions, University of Southern Queensland, Toowoomba, QLD, \\ Australia
}

* Corresponding author: Professor Suzanne Chambers, Menzies Health Institute Queensland, Griffith University, Gold Coast Campus, Southport, QLD, 4222, Australia. Email:

suzanne.chambers@griffith.edu.au

Acknowledgements: Data were drawn from participants recruited for an RCT funded by an Australian NHMRC Project Grant (ID:APP1024989).

Clinical Trial Registry: Trial Registration ACTRN12612000306819

Word count: 1497 excluding references 


\section{Key Points}

- The Five Facets of Mindfulness Questionnaire (FFMQ) has been widely used for patients with non-communicable disease, including cancer, but not validated with this population.

- Study purpose was to validate the factor structure of the FFMQ in men with advanced prostate cancer.

- Confirmatory factor analysis showed poor model fit for the original five facets.

- Exploratory factor analysis showed a six-factor solution (53.2\% variance explained) in which 'Act with awareness' separated into two facets; one reflecting awareness and the other focussed attention.

- Further research is needed to confirm these findings and establish stability of the FFMQ structure in cancer populations.

Keywords: Mindfulness, Prostate Cancer, Validity, Five Facets of Mindfulness Questionnaire, Factor Analysis 


\section{Introduction}

Mindfulness interventions are increasingly popular in cancer care, emerging in both literature and practice $[1,2]$. Evidence suggests mindfulness is helpful for women diagnosed with breast cancer [1] but this may not be the case in other settings [3]. In order to understand when, how, and which mindfulness skills promote effective coping with cancer, wellvalidated measures are needed.

The Five Facets of Mindfulness Questionnaire (FFMQ) [4] is a self-report measure of engagement in mindfulness practices. The five facets include: observing or noticing ones' reaction; ability to describe this reaction; acting with awareness; non-judging of inner experience; non-reactivity to inner experience. The FFMQ was originally validated with university students [4], and is widely used to measure mindfulness for patients with noncommunicable disease (depression [5]), including cancer [1, 2]. However, these studies overrepresent women with breast cancer; present a factor structure which differs in clinical populations from that originally proposed [5]; and none examine construct validity of the FFMQ in cancer populations. Accordingly, we validated the FFMQ using confirmatory factor analysis (CFA) in men diagnosed with advanced prostate cancer (PCa).

\section{Method}

Baseline data were obtained (pre-trial commencement) from 190 Australian men diagnosed with metastatic PCa or castration-resistant biochemical progression participating in a randomised controlled trial of a mindfulness intervention [3]. Participants gave written informed consent. Griffith University and participating hospitals granted ethics approval. Men were mean age 70.8 years $(\mathrm{SD}=8.7) ; 75 \%$ married/de-facto; $66 \%$ university/college educated; $68 \%$ retired; mean 6 years since diagnosis $(\mathrm{SD}=4.9)$. Men completed FFMQ, Brief Symptom Index, Functional Assessment of Cancer Therapy-PCa and Impact of Events scales. Full trial details are reported elsewhere $[3,6]$. 
CFA with maximum likelihood estimation was conducted using AMOS 22.0. Good model fit criteria were: non-significant chi-square, comparative fit index $(\mathrm{CFI})>0.9$; standardised root mean square residual (SRMR) and residual mean square error of approximation (RMSEA) $\leq 0.08$ [7]. Akaike Information Criterion (AIC) compared fit across models; lower scores indicate better fit [8]. Exploratory factor analysis (EFA) (maximum likelihood with oblimin rotation allowing correlation between factors [7]), and Kaiser normalization examined the structure solution best representing the data.

\section{Results}

Preliminary checks confirmed data were factorable (Bartlett's test of sphericity $=4075.78, \mathrm{df}=741, \mathrm{p}<0.05 ;$ Kaiser-Meyer-Olkin measure of sampling adequacy $=0.87$; communalities $>0.30$ ). Both the five-factor model and alternative hierarchical five-factor model proposed by Baer [4] were tested and proved to be a poor fit (Table 1).

The EFA produced an eight-factor solution initially, but Cattell's scree test and eigenvalues $>1$ indicated a six-factor solution. A second EFA constrained the analysis to sixfactors (53.2\% total variance; Table 2) which broadly replicated the FFMQ, except 'Act with awareness' emerged as two separate factors. One factor contained items reflecting being on auto-pilot which if reverse scored (as per original scale scoring) is consistent with the original 'Act with awareness' facet. The second factor contained items reflecting distraction which if reverse scored represents attention (Focused attention). This structure was replicated 9months post-trial completion (except item 36 which loaded onto the Observing factor).

Factors had adequate to good internal consistency (Table 2). Mindfulness facets showed small to moderate significant correlations between factors ranging from $r=0.03$ (Focused attention and Non-reactivity) to $r=0.56$ (Act with awareness and Focused attention). Bivariate correlations indicated small to moderate significant correlations between 
factors (except Non-reactivity). Significant correlations between factors, general and cancerspecific distress (negative correlation), and QoL (positive correlation) support convergent and divergent validity (Table 1), and concur with Baer [4].

\section{Discussion}

We replicated the original FFMQ factor structure [4] with the exception that a sixfactor model emerged dividing 'Act with awareness' into two facets. The first, Focused attention, contained items representing a person's capacity to be easily distracted and differed from the second facet, which included the remaining 'Act with awareness' items reflecting a person's tendency to operate on auto-pilot. This finding converges with cognitive psychological research in which awareness and attention are proposed as different mental processes (a person can be aware of a stimuli but it may not have their full attention) [9]. One implication of this finding is that mindfulness interventions may need to target these distinct variables. Chambers et al. [6] found that acting with awareness correlated with higher healthrelated quality of life and lower psychological distress for men in the current study. Further research is needed to establish if these outcomes relate to acting with awareness as well as focused attention, in order to determine on which facet(s) to intervene effectively.

Critical factors underlying and interacting with mindfulness may also differ for men and women (ability to identify and experience emotions) [2]; older adults may display higher levels of trait mindfulness (awareness of emotions/sensations without judgement) than younger adults [10]; and engagement with mindfulness may differ with illness or meditation experience [5]. Given the FFMQ was originally validated with predominantly young, female university students, who were inexperienced meditators [4], this study suggests the structure obtained may not be generalizable to male cancer populations. However, study limitations including the moderate sample size (within acceptable guidelines [7]), and non-assessment of meditation experience are noted. 
Better understanding of the relationship between mindfulness skills and cancer-related distress is needed and well-validated measurement is critical to achieve this. Further research validating the FFMQ structure in cancer populations will enable researchers and clinicians to confidently and accurately assess the mechanisms underpinning the effects of mindfulness interventions.

\section{References}

1. Piet J, Wurtzen, H, Zacharie R. The effect of mindfulness-based therapy on symptoms of anxiety and depression in adult cancer patients and survivors: A systematic review and meta-analysis. Journal of Consulting and Clinical Psychology. 2012;80(6):1007-1020.

2. Forti AM, Cashwell CS, Henson R. Mindfulness and quality of life in cancer survivors: the mediating role of self-kindness and alexithymia. Journal of Mental Health Counseling. 2016 Oct;38(4):346-59.

3. Chambers SK, Occhipinti S, Foley E, Clutton, Legg M, Berry M, Stockler MR, Frydenberg M, Gardiner RA, Lepore SJ, Davis ID, Smith, DP. Mindfulness-based cognitive therapy in advanced prostate cancer: A randomized controlled trial. Journal of Clinical Oncology. 2017;35(3):291-297. Doi: 10.1200/JCO.2016.68.8788

4. Baer RA, Smith GT, Hopkins J, Krietemeyer J, Toney L. Using self-report assessment methods to explore facets of mindfulness. Assessment. 2006; 13(1): 27-45.

5. Williams MJ, Dalgleish T, Karl A, Kuyken W. Examining the factor structures of the five facet mindfulness questionnaire and the self-compassion scale. Psychological assessment. 2014 Jun;26(2):407.

6. Chambers SK, Foley E, Clutton S, McDowall R, Occhipinti S, Berry M, Stockler MR, Lepore SJ, Frydenberg M, Gardiner RA, Davis ID, Smith DP. The role of mindfulness in distress and quality of life for men with advanced prostate cancer. Quality of Life Research. 2016; 25(12):3027-3035. 
7. Hair JF, Anderson RE, Tatham RL, Black WC. Multivariate Data Analysis . Englewood Cliff. New Jersey, USA. 1998.

8. Akaike H. Factor analysis and AIC. Psychometrika. 1987; 52(3):317-332.

9. Brown KW, Ryan RM. The benefits of being present: mindfulness and its role in psychological well-being. Journal of Personality and Social Psychology. 2003; 84(4):822848.

10. Mahoney CT, Segal DL, Coolidge FL. Anxiety sensitivity, experiential avoidance, and mindfulness among younger and older adults: age differences in risk factors for anxiety symptoms. The International Journal of Aging and Human Development. 2015; 81(4):217-240. 
Five Facets of Mindfulness and men with advanced prostate cancer 8

Table 1. Confirmatory factor analysis testing model fit of the FFMQ ( $n=175)$

\begin{tabular}{|c|c|c|c|c|c|c|}
\hline Model & $\chi 2(\mathrm{df})^{*}$ & CMIN/DF & CFI & SRMR & RMSEA & AIC \\
\hline Five-factor & $1654.25(692)$ & 2.39 & .74 & .17 & .09 & 1830.25 \\
\hline Five-factor hierarchical & $2922.10(702)$ & 4.16 & .39 & .29 & .13 & 3078.10 \\
\hline
\end{tabular}

$\mathrm{CMIN} / \mathrm{DF}=$ chi-square/df ratio.

*All $\chi 2$ statistically significant $p<0.001$ 
Table 2. Factor loadings of FFMQ items and correlations of factors with distress and QoL

\begin{tabular}{|c|c|c|c|c|c|c|}
\hline FFMQ Items & $\begin{array}{l}\text { Non- } \\
\text { reactivity } \\
\text { (F1) }\end{array}$ & $\begin{array}{l}\text { Observing } \\
\text { (F2) }\end{array}$ & $\begin{array}{c}\text { Focused } \\
\text { attention } \\
(\mathrm{F} 3)\end{array}$ & $\begin{array}{c}\text { Act with } \\
\text { Awareness } \\
\text { (F4) }\end{array}$ & $\begin{array}{l}\text { Describing } \\
\text { (F5) }\end{array}$ & $\begin{array}{c}\text { Non- } \\
\text { judging } \\
\text { (F6) }\end{array}$ \\
\hline 19..."step back"/aware of thought/image without taking over. & .543 & & & & & \\
\hline $21 \ldots$ pause without reacting. & .500 & & & & & \\
\hline 24...feel calm after distressing thoughts/images. & .524 & & & & & \\
\hline $29 \ldots$ notice distressing thoughts/images without reacting. & .840 & & & & & \\
\hline 33...notice distressing thoughts/images and let go. & .640 & & & & & \\
\hline 1...notice sensations of body. & & .567 & & & & \\
\hline 4...perceive emotions without reacting. & & .388 & & & & \\
\hline 6...stay alert to sensations on body. & & 608 & & & & \\
\hline 9...watch feelings without getting lost in them. & & .331 & & & & \\
\hline 11...notice foods/drinks affecting thoughts/sensations/emotions. & & .395 & & & & \\
\hline $15 \ldots$ pay attention to sensations. & & .783 & & & & \\
\hline $20 \ldots$ pay attention to sounds. & & .647 & & & & \\
\hline $26 \ldots$ notice smells/aromas. & & .485 & & & & \\
\hline $31 .$. notice visual elements. & & .461 & & & & \\
\hline 5...do things... mind wanders/distracted. & & & .738 & & & \\
\hline 8...don't pay attention doing because daydreaming/worrying/distracted. & & & 635 & & & \\
\hline $13 \ldots$..easily distracted. & & & .810 & & & \\
\hline 18...difficulty focusing on present. & & & .475 & & & \\
\hline 23..."running on automatic" without awareness of doing. & & & & .584 & & \\
\hline $28 \ldots$ rush activities without being attentive. & & & & .507 & & \\
\hline 34...do jobs/tasks automatically without awareness. & & & & .879 & & \\
\hline $38 . .$. do things without attention. & & & & .709 & & \\
\hline 2...good at describing feelings. & & & & & .702 & \\
\hline 7...easily put beliefs/opinions/expectations into words. & & & & & .701 & \\
\hline $12 \ldots$ hard to describe thoughts. & & & & & .489 & \\
\hline 16...trouble expressing feelings. & & & & & .582 & \\
\hline 22...difficulty describing sensations. & & & & & .375 & \\
\hline $27 \ldots$ when upset, can put into words. & & & & & .478 & \\
\hline $32 \ldots$ tendency to put experiences into words. & & & & & .777 & \\
\hline $37 .$. can describe feelings in-detail. & & & & & .728 & \\
\hline
\end{tabular}


3...criticize irrational/inappropriate emotions. $\quad \mathbf{. 4 5 2}$

$10 \ldots$ tell myself shouldn't feel this way. $\quad . \mathbf{7 2 4}$

$14 \ldots$ believe thoughts abnormal/bad. $\quad \mathbf{. 6 2 5}$

$17 .$. judge thoughts good/bad.

$25 .$. tell myself shouldn't think this way. $\quad \mathbf{. 6 7 5}$

30...think emotions bad/inappropriate.

$35 \ldots$ have distressing thoughts/images, judge myself good/bad. $\quad \mathbf{. 7 1 2}$

$36 .$. pay attention to emotions affecting thoughts/behavior.

$39 .$. disapprove irrational ideas.

$\begin{array}{lllllllll}\alpha & 0.80 & 0.81 & 0.90 & 0.83 & 0.86 & 0.88\end{array}$

\begin{tabular}{|c|c|c|c|c|c|c|}
\hline $\begin{array}{l}\text { Pearson's Correlations between Mindfulness Facets and Baseline } \\
\text { Outcome Measures }\end{array}$ & $\mathrm{F} 1$ & $\mathrm{~F} 2$ & F3 & $\mathrm{F} 4$ & F5 & F6 \\
\hline BSI & -.11 & $.20^{*}$ & $-.56^{*}$ & $-.46^{*}$ & $-.33 *$ & $-.62 *$ \\
\hline FACT-PCa & .12 & $-.15^{*}$ & $.48^{*}$ & $.40 *$ & $.34 *$ & $.51 *$ \\
\hline IES & -.02 & $.22 *$ & $-.47 *$ & $-.42 *$ & $-.31 *$ & $-.59 *$ \\
\hline
\end{tabular}

$\mathrm{F}=$ factor. Items with minimum loadings of 0.30 are displayed.

Items loading onto two factors were assigned based on the highest loading.

Bolded items correspond to item loadings on Baer's [4] original five facets.

$*=\mathrm{p}<.05$ 